\title{
Sciendo
}

Administration, vol. 70, no. 1 (2022), pp. 49-62

doi: 10.2478/admin-2022-0004

\section{Health services, 2021}

\author{
Fiona Keogh \\ Mental Health Ireland and NUI Galway, Ireland
}

\section{Covid-19}

Following a worrying start to the year with record high case numbers and over 2,000 people in hospitals with Covid-19, the health sector in 2021, along with other sectors, moved tentatively towards a 'new normal'. Unfortunately, 2021 ended much like 2020, with a new Covid-19 variant causing an exponential increase in cases and concerns about the impact on hospitals and the wider health service.

\section{Continuing spread of Covid-19}

Towards the end of 2020, Covid-19 cases were increasing rapidly and on 8 January 2021 a total of 8,248 cases were reported, at that time the highest number of confirmed cases recorded in a single day since the pandemic began. The highest number in hospital was 2,020 (18 January), and there were 221 people with Covid-19 in intensive care units (ICUs) on 24 January (Government of Ireland, 2022). This third wave of the pandemic was due to the Alpha variant (lineage B.1.1.7, initially called the English or UK variant), first detected in November 2020 in the UK. The numbers in hospital and ICUs did not approach these levels again in 2021, thanks to the successful vaccination programme.

A range of measures was brought into place in March in a bid to tackle the ongoing high number of cases, which were declining more slowly than anticipated. On 7 March legislation for mandatory hotel quarantine for certain passengers entering the country from high-risk 
countries was signed into law. From March onwards new walk-in Covid-19 test centres opened in a number of locations in an effort to bring down high case numbers in certain areas.

Although cases remained at around 300-400 daily, a reopening plan for the country was announced, with the Level 5 restrictions easing on various dates from early May. The milder weather allowed for increased socialisation outdoors. On 2 June the National Virus Reference Laboratory confirmed that there had been 115 cases of the Delta variant (lineage B.1.351, initially called the Indian variant) detected in Ireland. The number of cases began to creep up again, increasing to around 1,300 per day in July and around 1,800-2,000 per day in August. The vaccination programme was being rolled out very successfully through successive age cohorts (see below). This gave confidence in progressing the easing of restrictions and reopening the country. The progress the country had made in dealing with Covid-19 and the Delta variant was recognised, with Ireland being named number one in the Bloomberg Covid Resilience Ranking1 in September (Moore, 2021). Ireland remained high in this ranking and finished the year at number two.

\section{Omicron variant}

Throughout November the number of reported cases was approximately 3,000-5,000 per day. The numbers in hospital and ICU hovered around 200-300 and 30-40, respectively, and in spite of the high case numbers, there was some optimism that Christmas might be relatively 'normal'. However, the B.1.1.529 variant, later named the Omicron variant, was first reported to the World Health Organisation (WHO) from South Africa on 24 November (WHO, 2021). On 1 December the National Virus Reference Laboratory confirmed that the first case of the Omicron variant had been detected in Ireland. As with previous waves, this was a dynamic situation, with few firm data on the transmissibility and severity of this variant. Concerns around the variant led to the reintroduction of a series of measures, to run from 7 December to 9 January, including the closure of nightclubs,

\footnotetext{
1 The Covid Resilience Ranking is a monthly snapshot of where the virus is being handled the most effectively with the least social and economic upheaval. Compiled using twelve data indicators that span virus containment, quality of healthcare, vaccination coverage, overall mortality and progress toward restarting travel, it captures how the world's fifty-three biggest economies are responding to the Covid-19 threat. See https://www.bloomberg.com/graphics/covid-resilience-ranking/
} 
restrictions on bars and restaurants, and indoor cultural and sporting events to operate at 50 per cent capacity. These restrictions were subsequently increased to include 8 p.m. closing times for bars, restaurants, live events, cinemas and theatres, to run from 20 December to 30 January.

Cases increased throughout December, and on 24 December 11,182 cases were reported, with confirmation that 83 per cent of cases were now due to the Omicron variant (Bowers \& Clarke, 2021). The year ended with the highest daily cases reported since the start of the pandemic: 20,554 on 30 December. There was some hope that Omicron, while being highly transmissible, may not be as severe as the Delta variant, especially for people who had been vaccinated. While the numbers in hospital increased, they did not follow the surge that was seen at the end of 2020 and the numbers in ICU were not increasing substantially despite the increase in cases. Although there was resistance to the widespread deployment of antigen testing earlier in the year (Dáil Éireann, 2021a), the report of the Rapid Testing Expert Advisory Group in October concluded that 'Rapid Antigen Detection Tests can reliably detect those most likely to be infectious and the speed of the result enables rapid intervention to prevent onward transmission' (Rapid Testing Expert Advisory Group, 2021, p. 21). Antigen tests became a key tool in dealing with the Omicron wave, enabling people to test themselves for infection. They were subsequently recommended for use by close contacts.

\section{Covid-19 vaccination programme}

The 'game changer' in terms of the impact of Covid-19 on the health service, and daily life in general, in 2021 was the Covid-19 vaccination programme. The early stages of the programme were dogged by issues around supply uncertainty. In January there were reports of a shortfall in deliveries to the EU of the Oxford-AstraZeneca Covid-19 vaccine, resulting in Ireland receiving approximately 300,000 fewer doses than expected by the end of March. Nevertheless, in mid January around 1,800 healthcare workers received the Moderna Covid-19 vaccine at the first three mass vaccination centres that opened in Dublin, Galway and Portlaoise, and the first shipment of 21,600 AstraZeneca Covid-19 vaccines arrived in early February.

As per the Covid-19 Vaccine Allocation Strategy developed by the National Immunisation Advisory Committee (NIAC) in late 2020 (Department of Health, 2020), the first vaccinations were targeted at people living in long-term care facilities, healthcare workers and those 
aged over eight-five years. By 6 March 500,000 vaccines had been administered. At the end of March Minister for Health Stephen Donnelly, TD, announced an update to the Covid-19 Vaccine Allocation Strategy with priority groups being changed to an age-based system after vulnerable people with underlying conditions were vaccinated. This was based on the learning from the experience of the first phase of the programme and advice that this would be a simpler system to administrate. This decision was controversial and in early April the three teacher unions voted for an emergency motion backing industrial action, up to and including strike action, if they were not prioritised for vaccination. There were other controversies, for example, in the Coombe Women's Hospital and the Beacon Hospital, relating to the inappropriate administration of vaccines to individuals who were not in priority groups.

An online portal was developed to organise the administration of vaccines for the population aged under seventy years. On 5 April the portal opened for people aged sixty-nine years to register to receive a vaccine. People then received an appointment to attend for vaccination at a designated centre. The system worked throughout the year, with registration opened to successive age groups as the supply of vaccines increased. As soon as there was sufficient, reliable supply, the vaccination programme gathered pace and by June approximately 350,000 vaccines were being administered per week, with almost 400,000 vaccines administered in one week in early July. As of 31 December 2021, 94.4 per cent of the population aged eighteen years and older ${ }^{2}$ had been fully vaccinated and this rate was 92.4 per cent in the population aged twelve years and older (Health Protection Surveillance Centre, 2022). Ireland had the second-highest rate of full vaccination of the population aged eighteen years and older in the EU, after Denmark (European Centre for Disease Control, 2022).

Authorised Covid-19 vaccines for use in Ireland are Comirnaty (Pfizer/BioNTech), Spikevax (formerly Covid-19 Vaccine Moderna), Vaxzevria (formerly Covid-19 Vaccine AstraZeneca) and Covid-19 Vaccine Janssen. Most of the vaccines administered in Ireland were Pfizer (73.8 per cent), followed by AstraZeneca (15.6 per cent),

\footnotetext{
2 Overall population uptake is calculated based on Central Statistics Office (CSO) population estimates of 2021 (April 2021/H1), $n=4,963,363$ total. For eligible $12+$ year olds $n=4,152,710$, and for adults/ $18+$ year olds $n=3,745,527$. These are estimated total population sizes from the CSO in 2021, thus a tolerance of $+/-2$ per cent should be applied to any age group uptake data.
} 
Moderna (7.8 per cent) and Janssen ( 3 per cent). ${ }^{3}$ On 14 March the administration of the AstraZeneca Covid-19 vaccine was suspended in Ireland by the NIAC as a precautionary measure following concerns over serious blood clots in a small number of cases internationally. On 19 March the NIAC recommended that the AstraZeneca Covid-19 vaccine could continue to be used in Ireland following approval from the European Medicines Agency (EMA) on 18 March. On 8 April the Health Products Regulatory Authority investigated the first case in Ireland of a very rare blood clot in a woman after vaccination with the AstraZeneca vaccine. On 12 April the NIAC recommended that only people over sixty years of age should get the AstraZeneca Covid-19 vaccine and that a second dose of the vaccine should not be given to anyone who had developed unusual blood clots with low platelets after the first dose. Subsequently, it was announced in August by the Health Service Executive (HSE) that they would cease deliveries of the AstraZeneca and Janssen vaccines.

An expansion of the vaccination programme to younger people was announced in early July, and pharmacies began administering the Janssen vaccine to people in the eighteen to thirty-four age group who opted in for earlier vaccination from 5 July. Following recommendations from the NIAC, the vaccination programme was extended to those aged twelve to fifteen and by mid August more than 50,000 people in this age group had registered to receive the vaccine. On 25 November the EMA gave its approval for the use of the Pfizer vaccine in children aged five to eleven (EMA, 2021). The HSE commenced planning the vaccination of this age group for early January 2022.

\section{Booster}

Throughout autumn evidence began to emerge of waning immunity following vaccination, which prompted calls for the roll-out of a 'booster' vaccination programme ('Covid booster for over-65s', 2021). On 8 September an update to the vaccination programme was announced, with residents aged sixty-five years and older living in long-term residential care facilities and people aged eighty years and older living in the community to receive a booster dose of an mRNA Covid-19 vaccine. On 1 November the use of booster vaccines for healthcare staff was authorised. By the end of November and following the identification of the Omicron variant, it was announced that booster vaccines would be offered to everyone aged sixteen and

${ }^{3}$ See https://en.wikipedia.org/wiki/COVID-19_vaccination_in_the_Republic_of_Ireland 
over, starting with pregnant women aged over sixteen, those aged forty to forty-nine and those aged sixteen to thirty-nine.

\section{Covid-19 certificate}

In July 2021 a vaccine certificate programme was introduced, which was aligned with the EU Digital Covid Certificate. This is a digitally signed proof of vaccination, a recent recovery or a recent negative test, which allowed holders to attend cafes, bars and restaurants. On receipt of the required number of doses of vaccine, the Digital Covid Certificate was automatically sent to individuals. The certificate was later updated to include booster vaccinations.

\section{Cumulative numbers for the Covid-19 pandemic}

The cumulative numbers for key Covid-19 indicators since the beginning of the pandemic in March 2020 to the end of 2021 were: 761,850 confirmed cases of Covid-19 in Ireland; and 5,686 deaths among confirmed cases, a rate of 119.4 per 100,000 population. A total of 22,218 people had been hospitalised with Covid-19, with 2,335 admitted to ICU (Health Protection Surveillance Centre, 2022). ${ }^{4}$

\section{Cyberattack}

By May the vaccination programme was well underway, close to 200,000 people had received their first dose of a Covid-19 vaccine and the health system was beginning to 'draw breath' after the challenging beginning to 2021. However, on 14 May the HSE was the target of a major ransomware cyberattack, which caused all of its IT systems nationwide to be shut down. The Department of Health was also subject to a cyberattack at the same time. Irregular activity on their network was noticed on the afternoon of 13 May, although the attempt to run ransomware was unsuccessful. The Garda National Cyber Crime Bureau led the criminal investigation of both cyberattacks, working closely with the National Cyber Security Centre (NCSC). An Garda Síochána also liaised with international law enforcement agencies such as Interpol, Europol, the FBI and the UK's National Crime Agency. The Irish Defence Forces also worked with the HSE in resolving the attack.

\footnotetext{
${ }^{4}$ Data are provisional and subject to ongoing review, validation and update. As a result, figures in the HPSC report may differ from previously published and subsequently published figures.
} 
Severe disruption was caused to all aspects of the health service, with the attack being described as 'catastrophic' by Paul Reid, HSE chief executive (Black, 2021). It was reported that essential systems such as radiology and pathology laboratories were severely affected and that the number of appointments in some areas of the system dropped by 80 per cent as the system resorted to paper to keep essential services going. The Covid-19 vaccination programme was one of the few parts of the health system not to be affected and remained functioning throughout, although some elements of the Covid-19 response, such as the referral system for GPs, were affected.

An additional serious concern was that patient and staff information was accessed in the cyberattack. On 20 May the HSE obtained a high court injunction restricting any sharing, processing, selling or publishing of stolen data. While data relating to 520 patients were made public, there was no widespread sharing of patient or staff data following the attack (Lee, 2021).

Six weeks after the attack, at the Joint Oireachtas Committee on Health in June 2021, Reid reported that 75 per cent of HSE server capacity and 70 per cent of end-user devices had been decrypted, and that the overall cost to the HSE could amount to $€ 500$ million (Dáil Éireann, 2021b). By September, over 95 per cent of all servers and devices had been restored. A commitment was made by Minister of State Ossian Smyth, TD, who has responsibility for the NCSC, to expand the centre to counter the increasingly regular cyberthreats from criminal gangs and other sources. The ever-present threat of a cyberattack was highlighted when the Coombe Hospital was the target of a ransomware attack in December. Thankfully, the attack was contained and services were able to continue uninterrupted.

\section{Sláintecare}

The implementation of the Sláintecare programme of reform continued throughout 2021. The Sláintecare Implementation Strategy \& Action Plan 2021-2023 (Department of Health, 2021b) was published in May. The plan announced a focus on two reform programmes, with eleven projects, for 2021-3: 'Improving Safe, Timely Access to Care and Promoting Health \& Wellbeing'; and 'Addressing Health Inequalities'. A report on progress in the first six months of this strategy indicated that of the 112 deliverables, 84 were on track and a further 25 had been progressed with minor difficulties. The report 
identified three of the 112 projects - waiting lists, eHealth and regional health areas - as having a significant challenge. Action on two of these projects, the eHealth programme and regional health areas, was described as being 'severely hampered by the pandemic and the cyber-attack' (Sláintecare Programme Implementation Group, 2021, p. 15). In relation to waiting lists, the progress report noted that 'Actions to deliver the multi-annual plan have been drafted; ownership of actions and implementation oversight is still under consideration' (Sláintecare Programme Implementation Group, 2021, p. 14).

On 8 September Laura Magahy resigned as executive director of the Sláintecare programme. Professor Tom Keane, chairman of the Sláintecare Implementation Advisory Committee (SIAC), announced his resignation shortly after. It was reported that one of the reasons for Professor Keane's resignation was his belief that 'the requirements for implementing this unprecedented programme for change are seriously lacking' (Wall, 2021). On 17 September the Minister for Health, Stephen Donnelly, TD, met with the SIAC. A further meeting was held at the end of September when the advisory council met with Paul Reid and the Department of Health's secretary general, Robert Watt. Following this meeting, another member of the SIAC, Professor Anthony O'Connor, resigned. At a meeting of the Oireachtas Health Committee on 5 October, the Minister for Health announced the formation of a new Programme Board to oversee the implementation of Sláintecare, co-chaired by Watt and Reid, and comprising other senior members of the management teams of both the HSE and Department of Health. This new board had their first meeting in December.

An analysis of the resignations and their impact on the progress of Sláintecare indicated that the three projects on which little progress had been made seemed to be the central difficulty (Bowers, 2021). In her resignation letter, Magahy wrote: 'the HSE wishes to defer implementation of the Regional Health Areas, but it is my considered view that reform cannot happen without devolution of budgets on a population health basis, and clinical oversight on a regional basis, with supporting eHealth solutions. As we have discussed on several occasions, implementing these reforms requires a governance and oversight structure other than that which exists at present, in particular in light of the substantial additional funding being allocated towards the reform of the health service' (Bowers, 2021). This latter point was also made by Professor Keane in his resignation letter. The pause on 
establishing the six planned regional health areas was at the request of Reid, due to the pandemic. The SIAC agreed that pausing the move to regional health areas during the pandemic was the correct course of action.

Action on waiting lists was one of the three areas that had not been progressed and was cited as a key concern of Professor Keane and Magahy. In early October a Waiting List Action Plan was announced by Minister Donnelly, with deliverables across five areas, including waiting list management, immediate capacity and improved modernised pathways.

\section{Industrial relations}

The public service pay deal was formally ratified by trade unions in February. The deal received the backing of large public service representative organisations such as Fórsa, SIPTU, the Irish Nurses and Midwives Organisation (INMO) and others, although an Irish Medical Organisation ballot rejected the deal.

In March health service trade unions referred their claims to the Workplace Relations Commission (WRC) for compensation in recognition of their contribution for dealing with the Covid-19 pandemic. While the broader group of trade unions which represent virtually all grades of staff across the health system lodged a claim for 'special recognition', the INMO specifically sought ten days' additional leave for its members. In August the health sector trade unions referred a request for a pandemic bonus to the Labour Court following unsuccessful talks with the HSE in the WRC. In September Taoiseach Micheál Martin, TD, said the government was exploring a combination of measures - including payments and time off work - to mark the contribution of frontline workers during the pandemic (O'Halloran \& McQuinn, 2021). However, concerns were expressed about the high cost, estimated by the HSE as $€ 377$ million. In September the Labour Court recommended that all parties should 'make every effort possible' to begin 'effective engagement' to 'achieve clarity ... at the earliest possible opportunity' ('The single most costly claim', 2021).

In May public health specialists settled a twenty-year dispute with the Department of Health and the HSE over their regrading as consultants. Under the agreement, the HSE will create eighty-four consultant posts in public health for the first time. These appointments will be made on the terms of the Common Consultant Contract. A new 
model for public health medicine, with a reformed operating and governance structure, will also be delivered as part of the agreement.

Following on from the Longer Term Review: Matters Relating to Student Nurses and Midwives report (McHugh, 2021), additional supports worth $€ 12$ million were allocated for student nurses and midwives while attending their clinical placements.

In November medical laboratory scientists voted to take industrial action, including strike action, in a long-running dispute over pay. They are seeking the restoration of pay parity with scientific colleagues who work in biochemistry laboratories which they maintain was lost in 2002. Any industrial action by this group could take place early in 2022 .

\section{Other developments}

An important issue for Sláintecare and the wider health system is the development of a Health System Performance Assessment (HSPA) process to measure, monitor and report against the objectives of Sláintecare and broader policy and decision-making cycles. The newly developed HSPA framework was presented in September and work on its implementation is ongoing. The HSPA project was supported by the European Commission Structural Reform Support Service, which provided funding for the Phase 1 development, and the University of Amsterdam is the project provider.

A Women's Health Taskforce was established in September 2019 by the Department of Health to improve women's health outcomes and experiences of healthcare. One of the four priorities within its initial two-year action programme was to improve supports for menopause. In line with this, a commitment to provide four specialist menopause clinics around Ireland was made in September 2021, with the first clinic opening in December in the National Maternity Hospital.

\section{Legislation}

The Draft Heads of Bill to Amend the Mental Health Act were approved by government on 13 July 2021. The draft heads are primarily based on the 165 recommendations of a 2015 Expert Group Review of the Act, as well as the results of a 2021 public consultation, and an extensive consultation with key stakeholders such as the Mental Health Commission and HSE, and include domestic legislative 
changes in Ireland, including the Assisted Decision-Making (Capacity) Act 2015 and the Mental Health (Amendment) Act 2018. They also take account of Ireland's international obligations, including the UN Convention on the Rights of Persons with Disabilities, the UN Convention on the Rights of the Child and the European Convention on Human Rights.

The Nursing Homes Support Scheme (Amendment) Act 2021 was signed into law on 22 July and commenced in October. The legislation provides for various changes to the scheme (more commonly known as the Fair Deal Scheme). The primary amendment is that after a period of three years, when calculating the cost of a person's nursing home care, the value of family-owned farms and businesses will no longer be taken into account. The 2021 Act will also extend the existing threeyear cap on contributions to the cost of care to the proceeds of sale of a person's principal residence.

In other legislative or pre-legislative developments, further sections of the Public Health (Alcohol) Act 2018 were commenced and regulations were published to restrict price promotions of alcohol products.

The drafting of a General Scheme and Heads of a Bill to establish a licensing framework for publicly funded, for-profit and not-for-profit home support providers is underway. This is an important element of the long-awaited regulatory framework for home support services. It is envisaged that this framework will also include minimum requirements (regulations) upon which the regulator will develop a licensing system for home care providers.

Significant amendments to the Health Research Regulations 2018 were announced in January. These regulations provide the legal framework that governs the collection, use and sharing of an individual's personal information for health research purposes.

\section{Appointments}

Following a Top Level Appointments Committee competition, Robert Watt was appointed secretary general in the Department of Health in April. Watt was formerly the secretary general of the Department of Public Expenditure and Reform and had been undertaking the role on an interim basis since January 2021. There was some controversy over the manner of the interim appointment and the $€ 292,000$ salary for the post, which included a salary increase of $€ 81,000$. A report of the Joint Committee on Finance, Public Expenditure and Reform, and 
Taoiseach described the 'lack of transparency and the absence of any formal process in both the selection of the interim Secretary General and the sanctioning of a large pay increase. It [the examination by the Committee] also clarified that the whole process was managed by a small group in an ad hoc fashion' (Joint Committee on Finance, Public Expenditure and Reform, and Taoiseach, 2021, p. 6). Watt waived the $€ 81,000$ salary increase 'until the economy begins to recover and unemployment falls' (Department of Health, 2021a).

Anne Carrigy and Brendan Whelan were appointed to the board of the HSE following a Public Appointments Service campaign seeking additional members to the board. Whelan is appointed under the 'Patient Advocacy' provision and Carrigy under the provision requiring the candidate to have practised as a member of a health profession.

\section{References}

Black, R. (2021, 20 May). HSE chief details impact of 'stomach-churning' cyberattack. Retrieved from https://www.breakingnews.ie/ireland/hack-ofhealth-it-system-has-had-catastrophic-impact-says-hse-chief-1130092.html [20 December 2021].

Bowers, F. (2021, 9 October). Slaintecare drama may help clear reform path. Retrieved from https://www.rte.ie/news/2021/1009/1252568-slaintecareanalysis/ [20 December 2021].

Bowers, S., \& Clarke. V. (2021, 24 December). Covid-19: 11,182 new cases reported in state, with 83 per cent estimated to be Omicron variant. Retrieved from https://www.irishtimes.com/news/health/covid-19-11-182-new-casesreported-in-state-with-83-estimated-to-be-omicron-variant-1.4763760 [14 January 2022].

Covid booster for over-65s in care homes and everyone aged 80 plus. (2021, 8 September). Retrieved from https://www.rte.ie/news/2021/0908/1245475covid-vaccine-ireland/ [6 January 2022].

Dáil Éireann. (2021a). Joint Committee on Transport and Communications debate. Rapid antigen testing: Discussion (resumed). 16 June. Dáil Debates.

Dáil Éireann. (2021b). Update on the cyberattack, Covid-19 vaccination rollout, and Covid-19 restrictions in maternity hospitals: Health Service Executive. 23 June. Dáil Debates.

Department of Health. (2020). National Covid-19 vaccination strategy and implementation plan. Retrieved from https:/www.gov.ie/en/publication/ bf337-covid-19-vaccination-strategy-and-implementation-plan/ [12 January 2022]. 
Department of Health. (2021a). Robert Watt appointed secretary general at the Department of Health. Press release. Retrieved from https:/www.gov.ie/en/ press-release/a2088-robert-watt-appointed-secretary-general-at-thedepartment-of-health/ [14 January 2022].

Department of Health. (2021b). Sláintecare implementation strategy \& action plan 2021-2023. Retrieved from https://www.gov.ie/en/publication/6996bslaintecare-implementation-strategy-and-action-plan-2021-2023/ [12 January 2022].

European Centre for Disease Control. (2022). Country overview report week 52. Retrieved from https://covid19-country-overviews.ecdc.europa.eu/vaccin ation.html [6 January 2022].

European Medicines Agency. (2021). Comirnaty Covid-19 vaccine: EMA recommends approval for children aged 5 to 11 . Retrieved from https://www.ema.europa.eu/en/news/comirnaty-covid-19-vaccine-emarecommends-approval-children-aged-5-11 [6 January 2022].

Government of Ireland. (2022). ICU, acute hospital and testing data. Retrieved from https://covid19ireland-geohive.hub.arcgis.com/pages/hospitals-icutesting [16 January 2022].

Health Protection Surveillance Centre. (2022). Weekly report on the epidemiology of COVID-19 in Ireland Week 52, 2021. Retrieved from https://www.hpsc.ie/ [6 January 2022].

Joint Committee on Finance, Public Expenditure and Reform, and Taoiseach. (2021). Report on the processes and procedures applying to the appointment of senior executives in the public service. Dublin: Houses of the Oireachtas.

Lee, G. (2021, 28 May). HSE says stolen sensitive data of 520 patients on dark web. Retrieved from https://www.rte.ie/news/2021/0528/1224527-cyberattack-hse/ [20 December 2021].

McHugh, S. (2021). Longer term review: Matters relating to student nurses and midwives. Retrieved from https://www.gov.ie/en/publication/b8891-longerterm-review-of-matters-relating-to-student-nurses-and-midwives-mchughreport/ [20 December 2021].

Moore, J. (2021, 28 September). Ireland named 'best country' for response to pandemic in Bloomberg monthly resilience ranking. Retrieved from https://www.thejournal.ie/ireland-best-country-for-covid-response5560392-Sep2021/ [12 January 2022].

O’Halloran, M., \& McQuinn, C. (2021, 23 September). Pandemic bonus: Taoiseach says there may be a combination of pay and time off, including for retail staff. Retrieved from https://www.irishtimes.com/news/politics/ oireachtas/pandemic-bonus-taoiseach-says-there-may-be-a-combinationof-pay-and-time-off-including-for-retail-staff-1.4681863 [12 December 2021].

Rapid Testing Expert Advisory Group. (2021). Rapid testing in the context of the COVID-19 pandemic. Retrieved from https://www.gov.ie/en/publica tion/7d9ec-the-minister-for-health-stephen-donnelly-td-has-published-theinterim-report-of-the-expert-advisory-group-on-rapid-testing-rteag/ [12 January 2022]. 
Sláintecare Programme Implementation Group. (2021). Sláintecare progress report January - June 2021. Retrieved from https://www.gov.ie/en/publica tion/cce45-slaintecare-mid-year-progress-report-for-2021/ [14 January 2022].

'The single most costly claim on an employer' - Healthcare workers' Covid claim for ten days leave for staff 'would cost $€ 377$ m' HSE says. (2021, 22 September). Retrieved from https://www.independent.ie/irish-news/thesingle-most-costly-claim-on-an-employer-healthcare-workers-covid-claimfor-ten-days-leave-for-staff-would-cost-377m-hse-says-40877142.html [12 December 2021].

Wall, M. (2021, 9 September). Sláintecare chairman resigns due to unhappiness over delivery of healthcare reforms. Retrieved from https://www.irishtimes.com/news/health/sl per centC3 per centA1intecarechairman-resigns-due-to-unhappiness-over-delivery-of-healthcarereforms-1.4668711 [14 January 2022].

World Health Organisation. (2021). Classification of Omicron (B.1.1.529): SARS-CoV-2 variant of concern. Retrieved from https://www.who.int/news/item/26-11-2021-classification-of-omicron(b.1.1.529)-sars-cov-2-variant-of-concern [14 January 2022]. 